\title{
Diversity and antibiotic resistance of Aeromonas spp. in drinking and waste water treatment plants
}

\author{
Vânia Figueira, Ivone Vaz-Moreira, Márcia Silva, Célia M. Manaia* \\ CBQF/Escola Superior de Biotecnologia, Universidade Católica Portuguesa, R. Dr. António Bernardino de Almeida, $4200-072$ Porto, Portugal
}

Keywords:

Aeromonas

Quinolone resistance

Surface water

Waste water

\begin{abstract}
A B S T R A C T
The taxonomic diversity and antibiotic resistance phenotypes of aeromonads were examined in samples from drinking and waste water treatment plants (surface, ground and disinfected water in a drinking water treatment plant, and raw and treated waste water) and tap water. Bacteria identification and intra-species variation were determined based on the analysis of the 16S rRNA, gyrB and cpn60 gene sequences. Resistance phenotypes were determined using the disc diffusion method.

Aeromonas veronii prevailed in raw surface water, Aeromonas hydrophyla in ozonated water, and Aeromonas media and Aeromonas puntacta in waste water. No aeromonads were detected in ground water, after the chlorination tank or in tap water. Resistance to ceftazidime or meropenem was detected in isolates from the drinking water treatment plant and waste water isolates were intrinsically resistant to nalidixic acid. Most of the times, quinolone resistance was associated with the gyrA mutation in serine 83. The gene qnrS, but not the genes qnrA, B, C, D or qepA, was detected in both surface and waste water isolates. The gene aac $\left(6^{\prime}\right)$-ib-cr was detected in different waste water strains isolated in the presence of ciprofloxacin. Both quinolone resistance genes were detected only in the species A. media. This is the first study tracking antimicrobial resistance in aeromonads in drinking, tap and waste water and the importance of these bacteria as vectors of resistance in aquatic environments is discussed.
\end{abstract}

\section{Introduction}

The genus Aeromonas comprises ubiquitous bacteria, considered indigenous to aquatic environments (Janda and Abbott, 2010). Members of this genus are able to inhabit surface water (rivers, lakes), sewage, drinking water (tap and bottled mineral), thermal waters and sea water (Biscardi et al., 2002; Maalej et al., 2003; Pablos et al., 2009). Some species, mainly the psychrophilic Aeromonas salmonicida and the mesophilic Aeromonas hydrophila and Aeromonas veronii are recognized causative agents of fish disease (Janda and Abbott, 2010). Aeromonas spp. are also important human opportunistic pathogens with ability to cause various types of diseases, which include intestinal, blood, skin and soft tissue and trauma-related infections (Aminov, 2009; Lamy et al., 2009; Janda and Abbott, 2010). Among the leading pathogenic species are A. hydrophila, Aeromonas caviae (later synonym of Aeromonas punctata) and A. veronii (Lamy et al., 2009). The environmental ubiquity associated with the potential pathogenicity of these bacteria has been illustrated also in recent

\footnotetext{
* Corresponding author. Tel.: +351 22 5580059; fax: +351 225090351 .

E-mail address: cmmanaia@esb.ucp.pt (C.M. Manaia).
} 
natural disasters (Dixon, 2008). Evidences for the waterhuman transmission of Aeromonas spp. are also available (Khajanchi et al., 2010).

Over the last years, a greater public awareness and scientific understanding of antimicrobial resistance contributed to consider environmental reservoirs and paths of dissemination as critical points for antimicrobial resistance control. Among such reservoirs and paths of dissemination, water environments in which enter antibiotic resistant organisms from human and animal sources play a pivotal role (Baquero et al., 2008; Kümmerer, 2009; Taylor et al., 2011). The importance of municipal waste water treatment plants as sources of antimicrobial resistance and the risks of contamination of surface waters has been demonstrated in numerous publications (e.g. Gõni-Urriza et al., 2000; Ferreira da Silva et al., 2007; Servais and Passerat, 2009; Novo and Manaia, 2010). As a consequence of surface and ground water contamination, emerges the hypothesis that antimicrobial resistance can reach drinking water, serving as a vehicle of resistance transfer to the water consumers. Indeed, antimicrobial resistance has been detected in drinking water (Schwartz et al., 2003; Faria et al., 2009; Xi et al., 2009; Vaz-Moreira et al., 2011). Considering this urban water cycle, ubiquitous bacteria, which can colonize different types of water, are of special interest to assess potential forms of antimicrobial resistance dissemination. Given their ubiquity and patterns of acquired antimicrobial resistance, members of the genus Aeromonas are good example of such bacteria.

In a recent comprehensive review on the genus Aeromonas, Janda and Abbott (2010) alerted for the little attention given to the general low susceptibility of aeromonads to various classes and combinations of antimicrobial agents. Nevertheless, the potential of aeromonads to develop and disseminate antibiotic resistance either in clinical settings or in the environment has been demonstrated in numerous publications (Walsh et al., 1997; Gõni-Urriza et al., 2000; Huddleston et al., 2006; Blasco et al., 2008; Cattoir et al., 2008; Gordon et al., 2008; Lamy et al., 2009; Arias et al., 2010a,b). Moreover, recent and emerging antibiotic resistance seems to be common in different species of Aeromonas. For instance, different variants of the plasmid-mediated quinolone resistance qur gene were detected in environmental isolates of the species A. punctata, Aeromonas media or Aeromonas allosaccharophila (Cattoir et al., 2008; Picão et al., 2008; Xia et al. 2010). In spite the ubiquity of aeromonads in aquatic environments and the likelihood to develop antimicrobial resistance, the ecology and patterns of resistance of members of this genus present in drinking and waste water treatment plants has not been addressed in scientific literature. The current work aimed at filling this gap and was based on the hypothesis that Aeromonas spp. could serve as a vehicle for antibiotic resistance dissemination within the urban water cycle. According to this hypothesis, this work was designed to track aeromonads and their antibiotic resistance profiles in different parts of the urban water cycle. Our main goal was the identification of major sources of antibiotic resistant aeromonads and of critical points for their elimination. Specifically, it was intended to i) identify the different aquatic environments within the urban water cycle where aeromonads are more prevalent, and possible factors contributing for their reduction; ii) determine the predominant species in each of those environments; iii) infer about the possible relationship Aeromonas species-antibiotic resistance pattern.

\section{Materials and methods}

\subsection{Water sampling}

Water samples were collected from different aquatic environments within an urban water cycle in the region of Northern Portugal (Fig. 1). These sites included: i) a drinking water treatment plant (WTP) and the respective distribution system, which supplies water to a population of about 1.5 million of inhabitants; ii) household tap water, served by the WTP and iii) a municipal waste water treatment plant (WWTP), serving 85000 inhabitant equivalents, in the same geographical area (Ferreira da Silva et al., 2006; Vaz-Moreira et al., 2011). In the WTP, samples were collected from raw surface water (A), ground water (alluvial wells) (B), after sand filtration and ozonation (C) and after chlorination (D), the drinking water final treatment step. Four samples were collected downstream the WTP, in the drinking water distribution system respectively, after the first or the second re-chlorination stations (E$\mathrm{H})$. Tap water samples were collected in eleven houses (I-S), from taps used 1-4 times a month, served by the WTP referred to above and situated within an area of $25 \mathrm{~km}$ (Vaz-Moreira et al., 2011). Waste water samples corresponded to raw (T) and treated waste water (U). Sites A to $\mathrm{H}$ (drinking water treatment plant and distribution system) were sampled in November 2007 and in September 2009, sites I to S (taps) were sampled in April, July and October 2009 and sites T and U (waste water treatment plant) were sampled nine times between November 2004 and November 2009.

\subsection{Isolation, enumeration and preliminary identification}

This work was integrated in a wider study designed to assess the diversity and antibiotic resistance of culturable bacteria, belonging to different groups, present in selected niches within the urban water cycle. For the microbiological characterization of the water samples it was used the membrane filtration method, as described before for waste and surface water (Ferreira da Silva et al., 2006; Vaz-Moreira et al., 2011). Volumes of $10-500 \mathrm{ml}$ (WTP, drinking water distribution system, taps) or of $1-10 \mathrm{ml}$ (WWTP) of water samples or decimal dilutions thereof were filtered through cellulose nitrate membranes $(0.45 \mu \mathrm{m}$ pore size, $47 \mathrm{~mm}$ diameter, Albet), which were placed onto different culture media and incubated up to 7 days. No selective culture medium for aeromonads was used. Aeromonas spp. analysed in this study were isolated among the culturable heterotrophs recovered on different culture media - Plate Count Agar (PCA, Pronadisa), on m-endo-agar-LES (Difco), on mFC agar (Difco), on Tergitol-7 agar (TTC, Oxoid), on Pseudomonas Isolation Agar (PIA, Difco), on R2A agar (Difco) or on Bile Esculin Agar (BEA, Pronadisa). The culture media PCA, PIA, BEA and R2A were incubated at $30^{\circ} \mathrm{C}$ and $\mathrm{mFC}$ agar, m-endo-agar-LES and TTC were incubated at $37{ }^{\circ} \mathrm{C}$. Given this work was designed to 


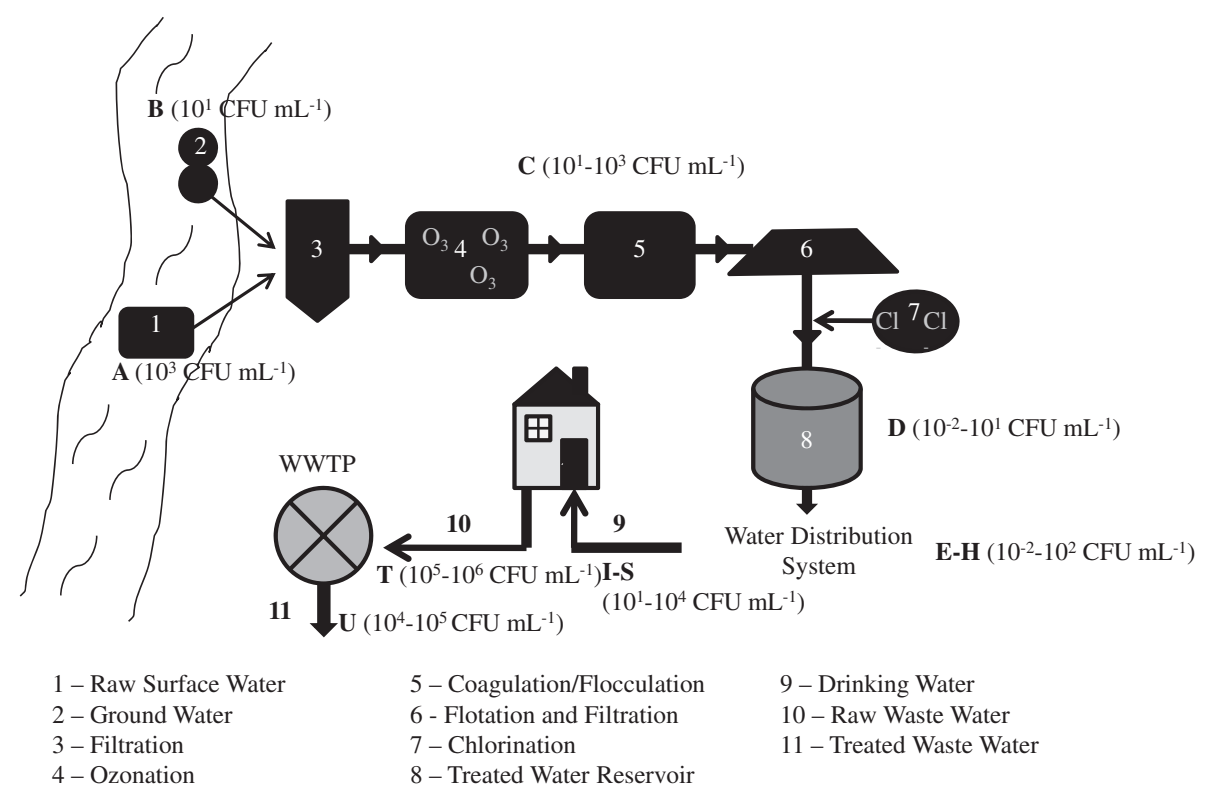

Fig. 1 - Schematic representation of the drinking and waste water treatment plants, indicating the treatment stages and sampled sites (A-U). Ground water disinfection involves only stages $6-7$. CFU mL ${ }^{-1}$ corresponds to culturable heterotrophic counts in the plates from which the aeromonads were isolated.

recover culturable bacteria from different bacterial groups, representatives of all colony types were selected for further culture isolation and purification, according to the following criterion: all colonies of morphotypes represented by less than five colonies, half of the colonies of morphotypes represented by five to 10 colonies, and about one third of colonies with morphotypes represented by more than 10 colonies. Cytochrome $c$ oxidase positive isolates with the morphology of Gram-negative rods and forming yellow colonies on GSP agar (Merck) at $30^{\circ} \mathrm{C}$ were presumptively identified as aeromonads (Corry et al., 2003; Abulhamd, 2009; Kivanc et al., 2011). This set of aeromonads included a total of 121 isolates, from which 72 and 8 were isolated, respectively, from the first and second sampling campaigns in the WTP; 1, 3, 2, 6, 1, 1, 5 and 13 were isolated, respectively, from each sampling date in the WWTP. A group of 9 WWTP isolates recovered on PCA or MFC agar supplemented with $4 \mathrm{mg} \mathrm{L}^{-1}$ ciprofloxacin (Applichem) (Novo and Manaia, 2010) were also examined in this study.

\subsection{Identification at the species level and determination of intra-species variation}

Identification at the species level was based on the analysis of the $16 \mathrm{~S}$ rRNA gene sequence and intra-species variation was assessed on basis of the comparison of two additional housekeeping genes, gyrB and cpn60 (Yáñez et al., 2003; Miñana-Galbis et al., 2009). PCR amplifications of fragments of the genes $16 \mathrm{~S}$ rRNA, gyrB and cpn60 were conducted using the primers and the conditions described before (Table 1). PCR products were purified with GFX PCR DNA purification kit (GE Healthcare) and the nucleotide sequences were determined.

Partial nucleotide sequences of the genes $16 \mathrm{~S}$ rRNA, gyrB and cpn60 were aligned using Clustal W from MEGA 4.0 software (Tamura et al., 2007) and compared with the homologous sequences of the type strains of the different Aeromonas species, available in the GenBank database. For the gene cpn60, the nucleotide sequences of the type strains of the species Aeromonas sanarellii and Aeromonas taiwanensis were not available in the GenBank database, and were determined in this study using the type strains provided by BCCM/LMG culture collection with the numbers LMG $24682^{\mathrm{T}}$ and LMG $24683^{\mathrm{T}}$, respectively. These nucleotide sequences were deposited in the GenBank database with the accession numbers JF920655 and JF920656 for A. sanarellii and A. taiwanensis, respectively

Nucleotide sequence relatedness was estimated based on the model of Jukes and Cantor (1969) and dendrograms were created using the neighbour-joining method. The maximumlikelihood method was also applied to assess tree stability. In the analysis were used 1283, 779 and 555 nucleotide positions of the 16S rRNA, gyrB and cpn60 gene sequences, respectively. Non-repetitive nucleotide sequences were deposited in the GenBank database with the accession numbers JF920473JF920563, JF938599-JF938689, and JF920564-JF920654 for 16S rRNA, gyrB and cpn60 sequences, respectively.

In an attempt to discriminate strains of the same species, each pair of isolates was compared based on the nucleotide sequence of each of the three genes. Strains differing at least in a nucleotide position were classified as representing distinct sequence types (ST). This comparison was represented in a dendrogram constructed based on 2617 nucleotide positions of the concatenated sequences of $16 \mathrm{~S}$ rRNA, cpn60 and gyrB genes (Fig. 2).

\subsection{Determination of antibiotic resistance phenotypes}

The susceptibility to 12 antibiotics was determined using the agar diffusion method (CLSI, 2007). The antibiotics tested were nalidixic acid (NA, $30 \mu \mathrm{g}$ ); ciprofloxacin (CIP, $5 \mu \mathrm{g}$ ); amoxicillin 


\begin{tabular}{|c|c|c|c|c|c|}
\hline Gene & Primers & Sequence & $\begin{array}{l}\text { Fragment length } \\
\text { (bp) }\end{array}$ & $\begin{array}{l}\text { Annealing temp. } \\
\left({ }^{\circ} \mathrm{C}\right)\end{array}$ & Reference \\
\hline \multirow[t]{2}{*}{ 16S rRNA } & $27 \mathrm{~F}$ & GAGTTTGATCCTGGCTCAG & 1465 & $55^{\circ} \mathrm{C}$ & Lane, 1991 \\
\hline & $1492 R$ & TAC CTT GTT ACG ACT T & & & \\
\hline \multirow[t]{2}{*}{ gyrB } & gyrB-3F & TCCGGCGGTCTGCACGGCGT & 1130 & $58^{\circ} \mathrm{C}$ & Yáñez et al., 2003 \\
\hline & gyrB-14R & TTGTCCGGGTTGTACTCGTC & & & \\
\hline \multirow[t]{2}{*}{ cpn60 } & C175 & GAAATYGAACTGGAAGACAA & 763 & $52{ }^{\circ} \mathrm{C}$ & Miñana-Galbis et al., 2009 \\
\hline & C938 & GTYGCTTTTTCCAGCTCCA & & & \\
\hline \multirow[t]{2}{*}{ gyrA } & AsalgyrAF & TCCTATCTTGATTACGCCATG & 481 & $50^{\circ} \mathrm{C}$ & Goñi-Urriza et al., 2002 \\
\hline & AsalgyrAR & CATGCCATACCTACCGCGAT & & & \\
\hline \multirow[t]{2}{*}{ parC } & AcparCF & GTTCAGCGCCGCATCATCTAC & 245 & $54^{\circ} \mathrm{C}$ & Goñi-Urriza et al., 2002 \\
\hline & EcparCR & TTCGGTGTAACGCATTGCCGC & & & \\
\hline \multirow{2}{*}{$q n r A$} & qnr Am F & AGAGGATTTCTCACGCCAGG & 580 & $54{ }^{\circ} \mathrm{C}$ & Cattoir et al., 2007 \\
\hline & qnrAm $R$ & TGCCAGGCACAGATCTTGAC & & & \\
\hline \multirow{2}{*}{$q n r B$} & $\mathrm{qnrBm} F$ & GGMATHGAAATTCGCCACTG & 264 & $54^{\circ} \mathrm{C}$ & Cattoir et al., 2007 \\
\hline & $\mathrm{qnrBm} R$ & TTTGCYGYYCGCCAGTCGAA & & & \\
\hline \multirow[t]{2}{*}{ qnrs } & qnrSm F & GCAAGTTCATTGAACAGGGT & 428 & $54^{\circ} \mathrm{C}$ & Cattoir et al., 2007 \\
\hline & qnrSm $\mathrm{R}$ & TCTAAACCGTCGAGTTCGGCG & & & \\
\hline \multirow[t]{2}{*}{$q n r C$} & qnrC-F & GGGTTGTACATTTATTGAATC & 447 & $50^{\circ} \mathrm{C}$ & Wang et al., 2009 \\
\hline & qnrC-R & TCCACTTTACGAGGTTCT & & & \\
\hline \multirow[t]{2}{*}{$q n r D$} & qnrD-F & CGAGATCAATTTACGGGGAATA & 582 & $55^{\circ} \mathrm{C}$ & Cavaco et al., 2009 \\
\hline & qnrD-R & AACAAGCTGAAGCGCCTG & & & \\
\hline \multirow[t]{2}{*}{$a a c\left(6^{\prime}\right)-I b$} & aac(6)-F & TTGCGATGCTCTATGAGTGGCTA & 482 & $55^{\circ} \mathrm{C}$ & Park et al., 2006 \\
\hline & $\operatorname{aac}(6)-R$ & CTCGAATGCCTGGCGTGTTT & & & \\
\hline \multirow[t]{2}{*}{ qep A } & qepA-F & TGGTCTACGCCATGGACCTCA & 1137 & $56{ }^{\circ} \mathrm{C}$ & Périchon et al., 2007 \\
\hline & qepA-R & TGAATTCGGACACCGTCTCCG & & & \\
\hline \multirow[t]{2}{*}{ cphA } & cphA-F & TCTATTTCGGGGCCAAGGG & 230 & $55^{\circ} \mathrm{C}$ & Balsalobre et al., 2009 \\
\hline & cphA-R & TCTCGGCCCAGTCGCTCTTCA & & & \\
\hline \multirow{2}{*}{ bla } & blaTEM fw & ATAAAATTCTTGAAGACGAAA & 939 & $55^{\circ} \mathrm{C}$ & DiPersio et al., 2005 \\
\hline & blaTEM rv & GACAGTTACCAATGCTTAATCA & & & \\
\hline
\end{tabular}

(AML, $25 \mu \mathrm{g}$ ); ticarcillin (TIC, $75 \mu \mathrm{g}$ ); cephalothin (CP, $30 \mu \mathrm{g}$ ); ceftazidime (CEF, $30 \mu \mathrm{g}$ ); streptomycin (STR, $10 \mu \mathrm{g}$ ); sulphamethoxazole/trimethoprim (SXT, $25 \mu \mathrm{g}$ ); tetracycline (TET, $30 \mu \mathrm{g})$; gentamicin (GEN, $10 \mu \mathrm{g})$; colistin sulphate (CT, $50 \mu \mathrm{g}$ ) and meropenem (MER, $10 \mu \mathrm{g})$. For the antibiotics AML and CT, which are not included in the CLSI list, were used the following criteria: $S \geq 21 / R<14$ and $S \geq 10 / R<10$, respectively. Whenever diameters larger than $\mathrm{R}$ but smaller than $\mathrm{S}$ were observed, were referred to as intermediary, and were excluded from the resistance percentage calculations. The strains Escherichia coli ATCC 25922 and Pseudomonas aeruginosa DSM 1117 (=ATCC 27853) were included as quality controls.

\subsection{Screening of resistance genetic determinants}

Mutations in the chromosomal genes gyrA and parC and the presence of resistance genes qnrA, qnrB, qnrS, qnrC, qnrD, $a a c\left(6^{\prime}\right)-I b$ and qepA were screened in quinolone resistant isolates. The presence of genes cphA and bla $\mathrm{TEM}_{\text {associated }}$ with beta-lactam resistance were screened in all isolates. The primers and PCR conditions used were described before (Table 1).

Point mutations in the genes gyrA and parC were identified after comparison with homologous nucleotide sequences of quinolone susceptible strains available in the GenBank - A. punctata CIP $7616^{\mathrm{T}}$ (AY027899 and AF435418), A. hydrophila subsp. hydrophila CIP $7614^{\mathrm{T}}$ (AY027901 and AF435419) and Aeromonas sobria CIP $7433^{\mathrm{T}}$ (AY027900 and AF435420) as described before (Goñi-Urriza et al., 2002). Strains E. coli L0 $(q n r \mathrm{~A} 1+)$, Klebsiella pneumoniae B1 (qnrB1 +) and Enterobacter cloacae S1 (qnrB4+ and qnrS1+) were used as positive controls for the presence of the determinants qnrA, qnrB and qnrS. The strains E. coli DH10B transformant pHS11 and E. coli DH10B transformant p2007057 were used as positive controls for qnrC and $q n r D$, respectively. Salmonella enterica serovar typhimurium GSS-HN-2007-003 was used as positive control (Xia et al., 2009) for the presence of gene $a a c\left(6^{\prime}\right)$-Ib. Strain E. coli TOP10 + pAT851 was used as positive control for gene qepA. PCR products were purified and the nucleotide sequences were determined and compared. A representative of each distinct nucleotide sequence was deposited in the GenBank (JF938596-JF938598).

\subsection{Statistical analysis}

The chi-squared test was used to compare the prevalence values of antibiotic resistance phenotypes or genotypes and sequence types in different water sampled sites (SPSS 19.0 for Windows, SPSS Inc., Chicago, IL).

\section{Results}

\subsection{Species diversity and intra-species variation}

A collection of 741 Gram-negative cytochrome c oxidasepositive isolates recovered on the culture media and conditions described above was screened for the presence of 


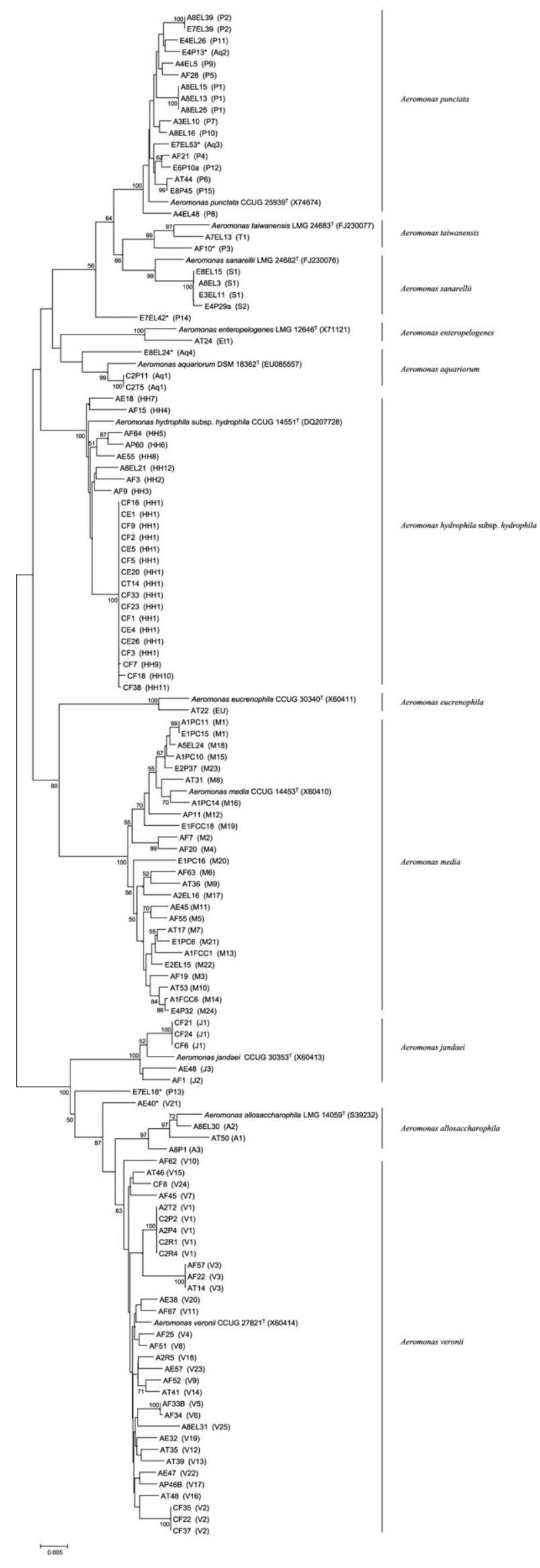

Aeromonas. On basis of $16 \mathrm{~S}$ rRNA gene sequence analysis, among these isolates, 121 ( 80 from the WTP, 32 from WWTP and nine from WWTP isolated in the presence of ciprofloxacin) were identified as belonging to 11 species of the genus Aeromonas. The other strains were affiliated to genera such as Pseudomonas, Ralstonia, Comamonas, Acidovorax, Brevundimonas, Cupriavidus, Chryseobacterium, Achromobacter and to the family Sphingomonadacae.

The group of Aeromonas spp. isolates comprised 80 from the drinking water treatment plant (51 from raw surface water - SC and 29 recovered after water ozonation - PO) and 32 from the waste water treatment plant (17 from raw - RWW and 15 from treated waste water - TWW). Additionally, nine aeromonads were isolated in the presence of ciprofloxacin (five from RWW and four from TWW). Aeromonads were not detected in ground water samples, neither downstream the chlorination tank of the WTP, including in tap water (Table 2, Fig. 1).

Aeromonas spp. identification to the species level (Table 2) was supported by the $16 \mathrm{~S}$ rRNA gene sequence analysis. Most of the times (114/121), these identifications were the same as those determined based on the analysis of the genes gyrB or cpn60. Only for seven isolates (five from TWW and two from SC) of the species Aeromonas aquariorum, A. punctata and A. veronii, the genes gyrB or cpn60 would lead to a different identification. Among the eleven species, eight were detected in raw surface water (Fig. 1, site A) and only four after the

Fig. 2 - Neighbour-joining dendrogram based on 16S rRNA, cpn60 and gyrB concatenated nucleotide sequences. Bootstrap values $(\geq 50 \%)$ generated from 1000 replicates are indicated at branch points. Bold circles indicate branches recovered by the maximum-likelihood method. Sequence types (ST) and16S rRNA GenBank accession numbers are indicated in parenthesis. GenBank accession numbers for cpn60 and gyrB sequences are, respectively, for $A$. allosaccharophila EU306795 and AY101777, A. aquariorum FJ936120 and EU268444, A. enteropelogenes EU306837 and EF465526, A. eucrenophila EU306803 and AY101776, A. hydrophila subsp. hydrophila EU306804 and AY101778, A. jandaei EU306807 and AY101780, A. media EU306808 and AY101782, A. punctata EU306800 and AY101783, A. sanarellii (JF920655) and FJ807277, A. taiwanensis (JF920656) and FJ807272, A. veronii EU306839 and AY101795.* Strains for which 16S rRNA based identification differed from that given by the genes gyrB and cpn60. Strains designation: Isolates from the drinking water treatment plant were generically designated as $\mathrm{SxMn}$, with $\mathrm{S}$ standing for site of isolation ( $A$, raw surface water; $C$, after ozonation), $x$ for the sampling date (2, second sampling date), $M$, for the culture medium of isolation (F, mFC agar; T, Tergitol-7 agar; $P$, Pseudomonas isolation agar; R, R2A agar; E, Bile Esculin agar), and $\mathbf{n}$ for the number of the isolate. Isolates from the raw or treated wastewater were generically designated as AxMn or ExMn, respectively (A relative to RWW and E to TWW); $\mathbf{x}$ for the sampling date; $M$ for the culture medium of isolation (P, PCA; PC, PCA with ciprofloxacin; EL, mendo-agar-LES; FC, MFC agar with ciprofloxacin); and $\mathbf{n}$ for isolate number of the isolate. 
Table 2 - Diversity and percentage (number of isolates, number of sequence types) of Aeromonas species in the different types of water.

\begin{tabular}{|c|c|c|c|c|}
\hline Species \% (n) & $\begin{array}{c}\text { Raw surface } \\
\text { water (51) }\end{array}$ & $\begin{array}{l}\text { After Ozonation } \\
\text { (29) }\end{array}$ & Raw Waste water (22) & $\begin{array}{c}\text { Treated Waste } \\
\text { water (19) }\end{array}$ \\
\hline A. allosaccharophila (3) & $2.0 \%(1,1)$ & - & $9.1 \%(2,2)$ & - \\
\hline A. aquariorum (5) & - & $6.9 \%(2,1)$ & - & $15.8 \%(3,3)$ \\
\hline A. enteropelogenes (1) & $2.0 \%(1,1)$ & - & - & - \\
\hline A. eucrenophila (1) & $2.0 \%(1,1)$ & - & - & - \\
\hline A. hydrophila subsp. hydrophila (25) & $13.7 \%(7,7)$ & $58.6 \%(17,4)$ & $4.5 \%(1,1)$ & - \\
\hline A. jandaei (5) & $3.9 \%(2,2)$ & $10.3 \%(3,1)$ & - & - \\
\hline A. media (25) & $19.6 \%(10,10)$ & - & $36.4 \%(8,8)$ & $36.8 \%(7,7)$ \\
\hline A. punctata (18) & $7.8 \%(4,4)$ & - & $36.4 \%(8,6)$ & $31.6 \%(6,6)$ \\
\hline A. sanarellii (4) & - & - & $4.5 \%(1,1)$ & $15.8 \%(3,2)$ \\
\hline A. taiwanensis (1) & - & - & $4.5 \%(1,1)$ & - \\
\hline A. veronii (33) & $49.0 \%(25,22)$ & $24.1 \%(7,3)$ & $4.5 \%(1,1)$ & - \\
\hline
\end{tabular}

No aeromonads were isolated from ground water or from any sampling point after water chlorination, including in 11 household taps.

ozonation process (Fig. 1, site C). Whereas in raw surface water the species A. veronii and A. media predominated, after ozonation, the species A. hydrophila subsp. hydrophila represented more than half of the isolates. The species A. media and A. punctata were not detected after the ozonation process. These same two species, A. media and A. punctata, prevailed in raw and in treated waste water (Table 2).

In order to infer about intra-species variability and to track bacteria in the different water samples, bacterial isolates were compared on basis of the nucleotide sequences of the genes $16 \mathrm{~S}$ rRNA, cpn60 and gyrB. This procedure allowed the identification of 91 sequence types (Table 2). For sake of simplicity, the relationship of the isolates was represented in a dendrogram based on the comparative analyses of the 16S rRNA, cpn60 and gyrB concatenated sequences (Fig. 2). Not surprisingly, the same sequence type was not detected in nondirectly-communicating water compartments, i.e, in surface and waste water. In contrast, the same sequence types were observed occasionally in communicating zones, separated by water treatment, i.e. ozonation or waste water treatment. In the drinking water treatment plant, the same sequence type of A. veronii (V1) was detected in raw surface water and after ozonation. In spite of this, water ozonation seemed to impose a serious bottleneck on strain diversity with the reduction of 48 sequence types in raw surface water to only nine in ozonated water. Moreover, the sequence types of A. hydrophila subsp. hydrophila detected in ozonated water (isolates C of sequence type HH1, Fig. 2) were, most of the times, distinct from those detected in raw surface water, suggesting that minor population representatives may have gained advantage under the oxidative stress imposed by ozone. In the waste water treatment plant, the same sequence types of the species A. media (M1), A. punctata (P2) and A. sanarellii (S1) were detected in raw and in treated waste water (Fig. 2) and P2 and S1 were also present in waste water samples collected in different dates.

\subsection{Antibiotic resistance phenotypes}

Amoxicillin resistance was observed in all isolates except in an Aeromonas enteropelogenes strain, suggesting that aeromonads are intrinsically resistant to this beta-lactam. For the other antibiotics, in general, the highest resistance prevalence values were observed for the penicillin ticarcillin and for the cephalosporin cephalothin, reaching percentages superior to $40 \%$, irrespective of the type of water. Resistance phenotypes to the cephalosporin ceftazidime and the carbapenem meropenem were observed at low rates, exclusively in surface water (Table 3). Ceftazidime resistance was observed in a single isolate of A. media of raw surface water. Meropenem resistance was observed in three isolates of $A$. veronii, before and after water ozonation. Colistin resistance was another rare phenotype, detected only after the ozonation process in two isolates of Aeromonas jandaei with the same sequence type, presumably representing the same strain.

Nalidixic acid resistance was about five times more prevalent among waste water isolates (90.6\%) than in surface water $(17.6 \%, p<0.001)$ and was not detected after ozonation (Table 3). In waste water, quinolone resistance was mainly related to the species A. media and A. punctata, which predominated in that type of water. Curiously, these two species were not observed after water ozonation, a fact that may explain the apparent efficiency of that disinfection process on quinolone resistance elimination. The potential of $A$. media as reservoir of quinolone resistance in waste water was confirmed by the fact that nine waste water strains (five from RWW and four from TWW) isolated in the presence of $4 \mathrm{mg} \mathrm{L}^{-1}$ of ciprofloxacin were all members of this species. These nine isolates, represented by eight distinct sequence types, were, not surprisingly, resistant to nalidixic acid and had at least an intermediary resistance phenotype to ciprofloxacin (four resistant and five intermediary). Six out of these nine strains were resistant to at least three different classes of antibiotics (R3) (gentamycin, tetracycline and sulfamethoxazole/ trimethoprim), exhibiting resistance phenotypes rare among the aeromonads isolated in the absence of ciprofloxacin. Multi-resistance was also frequent among A. punctata (six out of 18 isolates) (Table 3). In contrast, none of the $33 \mathrm{~A}$. veronii isolates presented resistance to three different classes of antibiotics, probably due to the fact that most of these isolates were recovered from raw surface or ozonated water. Multiresistance (R3) did not differ significantly between raw surface and ozonated water. In contrast, R3 was significantly $(p<0.05)$ higher in waste water than in raw surface water. 
Table 3 - Antibiotic resistance prevalence (\%) in the different sampled sites and Aeromonas species.

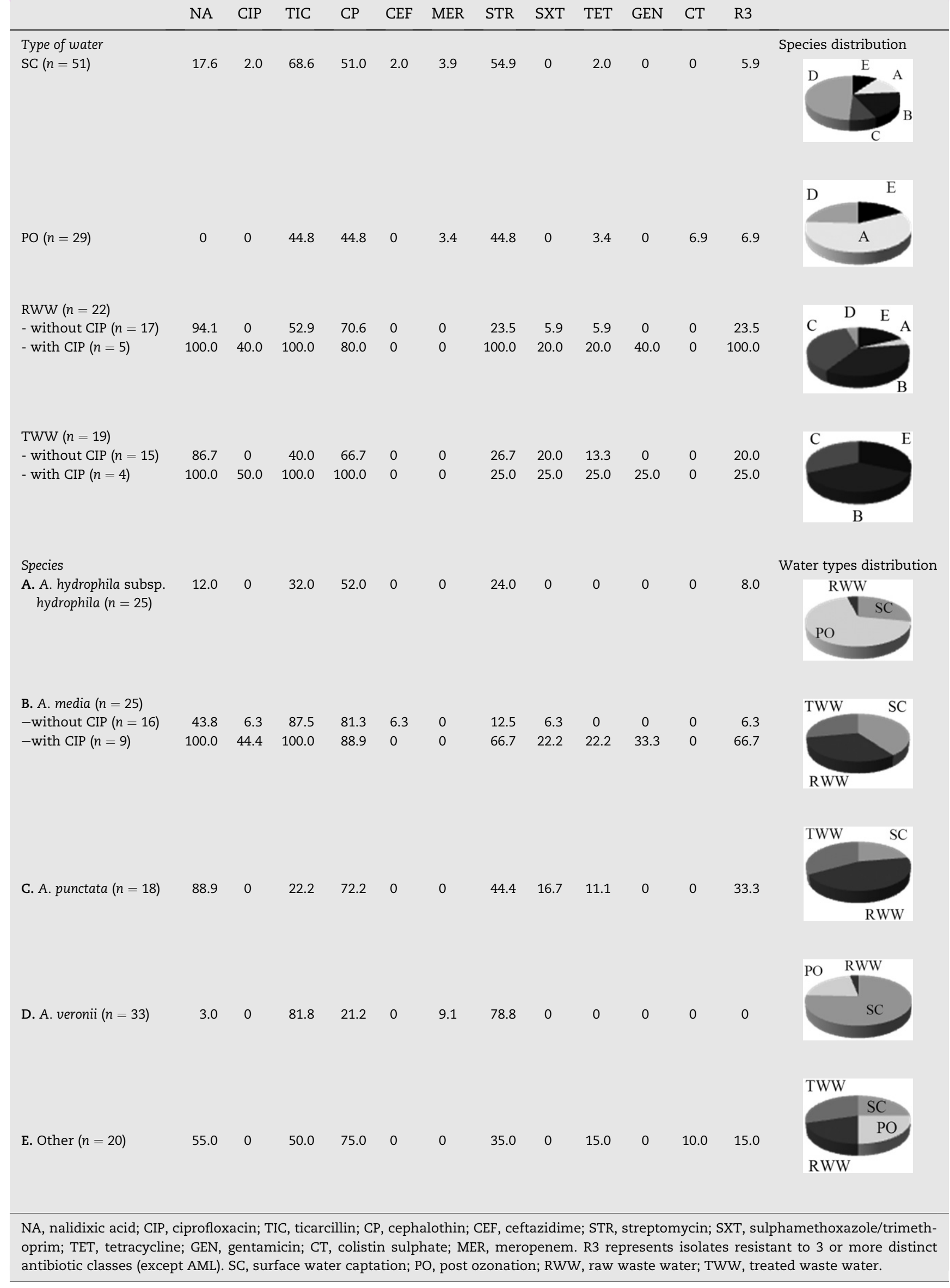




\subsection{Genetic determinants of quinolone resistance and cphA gene distribution}

Given the significantly higher prevalence of quinolone resistance in waste- than in surface water and in the species Aeromonas puntacta and A. media than in the others $(p<0.001)$ it was decided to investigate if similar mechanisms of resistance were present in both types of water and in the different species. Irrespective of the type of water or Aeromonas species, nalidixic acid resistance was associated with mutations in the gene gyrA $(n=45)$ and sometimes also on the gene parC $(n=15$ and a silent mutation) (Table 4). The most common gyrA mutations were transversions in the position 83 (AGC $\rightarrow$ ATC, in 31 isolates or AGT $\rightarrow$ ATT, in six isolates) corresponding to the substitution of a serine for an isoleucine residue. In two isolates, one of A. allosaccharophila and one of A. jandaei, it was not possible to achieve a successful amplification of the gene gyrA, even using alternative primer sets and protocols (n.d. in Table 4). Among the plasmid-mediated quinolone resistance, only the genes qnrS and $a a c\left(6^{\prime}\right)$-ib-cr were detected. Although being found exclusively in the species A. media (Table 4), these genes were observed in different strains (different sequence types). The gene qnrS was detected in strains of both surface and waste water, isolated either in the presence or in the absence of ciprofloxacin. The qnrS positive strains isolated in the presence of $4 \mathrm{mg} \mathrm{L}^{-1}$ ciprofloxacin harboured also the gene aac(6')-ib-cr which, in contrast to qurS, was associated with a resistance or intermediary phenotype for ciprofloxacin. The gene aac(6')-ib-cr was detected exclusively in strains isolated on ciprofloxacin-supplemented medium, suggesting that these strains represent a minor fraction of the bacterial population, which can gain advantage in the presence of selective pressure. One isolate from surface water harboured the gene aac (6')-ib, but not the $\mathrm{cr}$ variant that confers resistance to ciprofloxacin. The $\mathrm{cr}$ variant of the gene $a a c\left(6^{\prime}\right)$-ib presented mutations in the position 102, with an arginine residue (AGG or, in one RWW isolate, CGG) instead of tryptophan (TGG), on position 117, with a leucine residue (TTA) instead of serine (TCA) and on position 179, with a tyrosine residue (TAT) instead of an aspartate (GAT).

The most common metallo-beta-lactamase expressed by Aeromonas spp. is encoded by the chromosomal gene cphA, reported mainly in the species $A$. hydrophila, A. veronii and $A$. jandaei (Janda and Abbott, 2010). The presence and diversity of this gene was screened in an attempt to identify a differential pattern between isolates from the drinking and waste water treatment plants or between different species. The gene cphA was detected in the species Aeromonas allosacharophila (one isolate from SC and one isolate from RWW), A. aquariorum (2 isolates from $\mathrm{PO}$ ), A. hydrophila subsp. hydrophila (in all except in one isolate from SC and one from PO), A. jandaei (in all isolates) and A. veronii (in all except in one isolate from SC, seven from PO and one from RWW). Unexpectedly, it was also detected in a raw waste water isolate of the species A. media, recovered from ciprofloxacin-supplemented medium. The nucleotide sequences of the gene cphA were different among these isolates. However, those differences corresponded to silent mutations, as the amino acid sequences were identical among the waste- and drinking water treatment plant isolates (data not shown). Nevertheless, a noticeable contrast was found in terms of prevalence. The gene cphA was significantly $(p \leq 0.001)$ more prevalent among surface water (65\%) than in ozonated water (97\%) isolates. It was also significantly $(p<0.001)$ less prevalent $(18 \%)$ in the waste water treatment plant than in the drinking water treatment plant (76\%). None of the treated waste water isolates harboured the gene cphA (Fig. 3). The plasmid related beta-lactamase gene bla TEM $_{\text {was }}$ detected in a single raw waste water strain of A. media isolated on culture medium supplemented with $4 \mathrm{mg} \mathrm{L}^{-1}$ of ciprofloxacin, and which harboured also the gene aac(6')-ib-cr.

\section{Discussion}

This study was based on the hypothesis that Aeromonas spp. can serve as vehicle for antibiotic resistance dissemination within the urban water cycle. The experimental planning comprised the detection, diversity typing and determination of antimicrobial resistance patterns of aeromonads within different parts of the urban water cycle. In respect to detection, Aeromonas spp. were isolated from raw and treated waste water, as well as, from surface water, including after ozone disinfection. In contrast, culturable aeromonads were not detected in locations with pristine or disinfected water, ground and tap water, respectively. Apparently the drinking water treatment, mainly water chlorination, could remove aeromonads to, at least, less than one CFU in $100 \mathrm{~mL}$ of water. Although the failure to detect aeromonads in tap water could be attributed to low bacterial densities, in some taps, heterotrophs reached $10^{1}-10^{4} \mathrm{CFU} \mathrm{mL} \mathrm{m}^{-1}$ (Fig. 1). The presence of Aeromonas spp. in drinking water is undesirable, as may have implications for user health, mainly via contact transmission (WHO, 2008). Nevertheless, aeromonads have been detected in different types of drinking water, namely tap, mineral bottled and wells (Kühn et al., 1997; Biscardi et al., 2002; Pablos et al., 2009). Some authors referred to the seasonality of aeromonads, which increase may coincide with the raise in the environmental temperature (Janda and Abbott, 2010). In this study, a priori, the failure to detect Aeromonas spp. in ground and tap water cannot be attributed to such seasonality, given the fact that these samples were collected in Summer and Winter (ground water) or in Spring, Summer and Autumn (taps). It is noteworthy that the absence of culturable Aeromonas spp. in tap water contrasts to what was observed in the same samples for other bacterial groups. For example, it was observed that sphingomonads, pseudomonads, and Acinetobacter spp., in spite the sharp decrease of total heterotrophs observed after water chlorination, were present in tap water (Vaz-Moreira et al., 2011; our data unpublished). The fact that the examined taps had a low usage rate (one to four times a month) may be part of the possible explanation for the absence of Aeromonas in tap water, as stagnancy of water in pipes is described as promoting bacterial community rearrangements (Lautenschlager et al. 2010). However, a deeper study would be needed to confirm such hypothesis. Thus, the apparent reduced risk of Aeromonas spp. to contribute for 
Table 4 - Diversity, antibiotic resistance phenotypes, origin and genetic determinants of quinolone resistance of nalidixic acid resistant isolates.

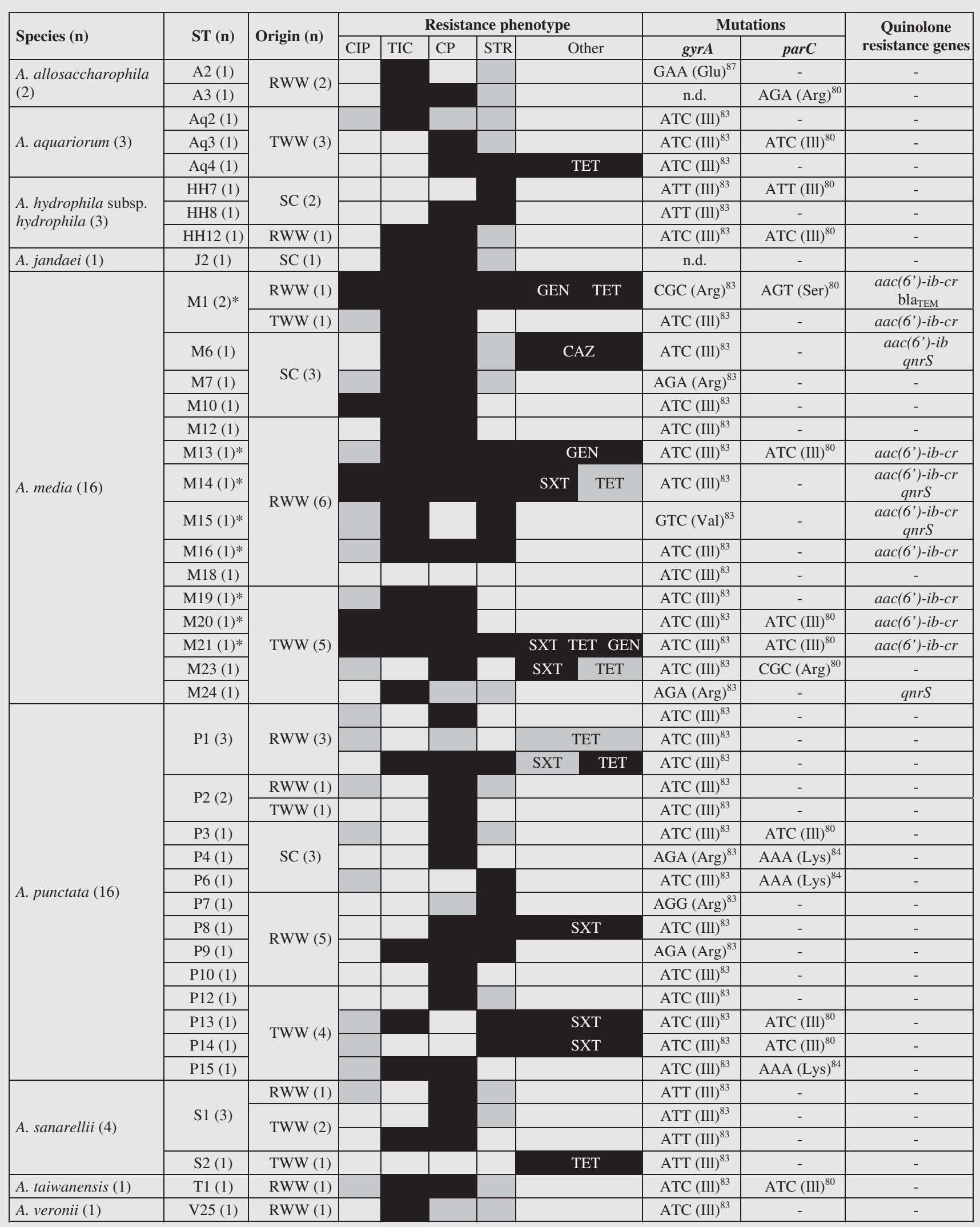

n.d., not determined; (shadowing; black, resistant; grey, intermediary; white, susceptible) .

* isolated in medium supplemented with $4 \mathrm{mg} \mathrm{L}^{-1}$ of ciprofloxacin. 


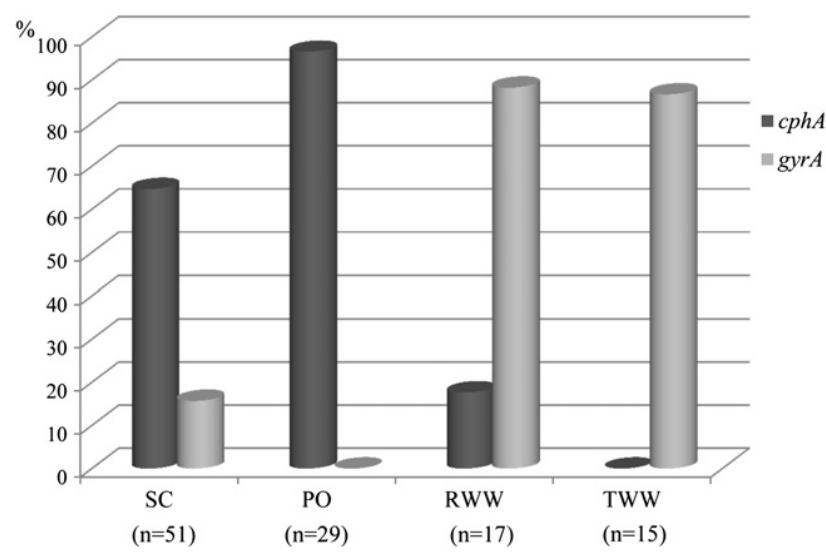

Fig. 3 - Percentage of isolates of each type of water that harbored the cphA gene or the gyrA mutation.

antimicrobial resistance dissemination via tap water, observed in this study, must be interpreted with precaution.

In respect to diversity, it was observed that the pattern of Aeromonas species was distinct in the different types of water. Although A. media was abundant in both raw surface and waste water, these types of water differed on the predominance of $A$. veronii and A. punctata (Table 2). Nevertheless, the percentage of distinct sequence types was not significantly different in surface and waste water. Apparently, and in spite the low number of isolates, waste water treatment did not lead to a significant reduction of the number of sequence types. In contrast, water ozonation seemed to impose a bottleneck both in the number of species and of sequence types (Fig. 2). Indeed, the species Aeromonas hydrophyla subsp. hydrophyla became over represented after ozonation with a significant $(p<0.001)$ reduction in the percentage of distinct sequence types. Moreover, in general, the sequence types detected after ozonation were different from those found in raw surface water, suggesting some kind of rearrangement in the aeromonads population due to water disinfection (Fig. 2).

A. media and A. punctata were the species in which quinolone resistance presented the highest prevalence $(p<0.001)$ and the predominance of these species in waste water contributed to explain the elevated rates of nalidixic acid resistance in waste water, significantly $(p<0.001)$ higher than in surface water. Similarly, sulfamethoxazole/trimethoprim resistance found exclusively in those two species, was observed only in waste water. In contrast, ceftazidime and meropenem resistance were detected only in surface water, although it is acknowledged that these resistance phenotypes could have been detected also in waste water if a larger number of isolates had been examined.

The search for genetic determinants related to quinolone resistance showed that the gyrA mutations were the primary, even not the unique, mechanism (Table 4). The higher prevalence of these mutations in waste water isolates in comparison with the prevalence values observed in surface water (Fig. 3), can be supported by previous studies which demonstrate that quinolone resistance may arise from the contact with mutagenic substances, widely found in the environment (Miyahara et al., 2011). In fact, in waste water the occurrence of such potential mutagens is much more probable than in uncontaminated waters. Additionally, some effect of selective pressure may take place in waste waters, in which the detection of quinolones is common, with concentrations of ciprofloxacin up to $0.7 \mu \mathrm{g} / \mathrm{L}$ detected in Portuguese municipal waste water treatment plants (Seifrtová et al., 2008; our data for the same plant, unpublished). It is not possible to know the relevance of de novo mutation or of selection (vertical transmission) for the observed chromosomal mutations associated with quinolone resistance. But, although probably both forms can contribute for resistance spreading, de novo events may be frequent as gyrA or parC gene mutations were observed in different strains (sequence types). In any case, the species A. punctata and A. media seem to play an important role on this form of dissemination. These results are in agreement with the work of Goñi-Urriza et al. (2000), who assessed the impact of an urban effluent on antibiotic resistance of Aeromonas spp. in a riverine area. As in the current study, nalidixic acid resistance was observed in the majority of the aeromonads (72\%), most of them of the species A. punctata (A. caviae), and was exclusively chromosomally encoded. The conclusion reached by Goñi-Urriza et al. (2000), applies also to the present study - urban effluents are responsible for the increase of quinolone resistance in the receptor water courses.

Among the quinolone resistance determinants associated with mobile genetic elements, only the genes qurS and aac(6')$\mathrm{ib}$-cr were detected and only in the species A. media. In both cases, these genetic determinants were found in different strains (sequence types), as expected if horizontal gene transfer is equated. Both determinants, and mainly aac(6')-ib-cr which was detected only in isolates recovered in the presence of ciprofloxacin, were rare in the analysed samples. Nevertheless, the gene qnrs is apparently widespread in waters (waste water, rivers, aquaculture), detected not only from total DNA and but also from cultures of aeromonads and Enterobacteriaceae (Cattoir et al., 2008; Picão et al., 2008; Szczepanowski et al., 2009; Ishida et al., 2010; Cummings et al., 2011). Similarly, the gene aac(6')-ib-cr is found in different types of water (lake water, river sediments, aquaculture), either in total DNA or in bacterial isolates (aeromonads and Enterobacteriaceae) (Picão et al. 2008; Ishida et al., 2010; Cummings et al., 2011). The presence of these genes, although conferring low-levels of resistance, can favour and complement the selection of other resistance mechanisms (Rodríguez-Martínez et al., 2010). The fact that the determinants qurs and $a a c\left(6^{\prime}\right)-i b-c r$ were detected only in A. media suggests that this species may represent an important vector of quinolone resistance. Ceftazidime resistance was also detected only in this same species in surface water. Recent evidences that water A. media can colonize humans (Khajanchi et al., 2010) may give additional relevance to this species on the dispersal of resistance. Although the number of isolates examined was too low to strongly support this conclusion, the data suggested that water ozonation may promote the reduction of A. media. For instance, no quinolone or ceftazidime resistance were observed downstream of this point. In contrast, meropenem resistance, in this study associated to the species A. veronii, was observed also in ozonated water. Nevertheless, the data gathered in this study suggests that water chlorination may contribute to control resistance propagation by aeromonads via drinking water. 
In general, the results obtained suggest that different aeromonads populations and antibiotic resistance determinants prevail in different parts of the urban water cycle. The clearest example of this was the distribution of the gene cphA and of the gyrA mutation, observed in the majority of the surface and waste water isolates, respectively (Fig. 3). As expected, the gene cphA was predominant among the species A. hydrophila subsp. hydrophila, A. veronii and A. jandaei, also the most prevalent in the drinking water treatment plant. In the same way, the gyrA mutations prevailed in A. media and A. punctata, the predominant species in waste water. The contrast observed in the distribution of both genetic determinants is mainly due to the patterns of species occurring in both types of water and which, probably, are due to the environmental conditions and selective pressures imposed in both types of habitat. This also demonstrates that, in each type of water, aeromonads may represent a source of distinct types of antibiotic resistance.

The importance of a given Aeromonas species for the antimicrobial resistance patterns in each type of water, observed in the current work, confirm previous studies conducted with other bacterial groups. Figueira et al. (2011) studied different populations of waste water E. coli and concluded that variations on the prevalence of quinolone resistance were correlated with the dynamics of some population sub-sets. VazMoreira et al. (2011) characterizing the patterns of antimicrobial resistance in sphingomonads from tap water and cup fillers of dental chairs also concluded that antibiotic resistance patterns were often species- rather than site-related. Nevertheless, in the current work, and in contrast to what was suggested by other authors studying A. salmonicida from fish farms and environmental samples (Giraud et al., 2004; Kim et al., 2011), no clonal spreading of antibiotic resistance was observed. In contrast, rarely were observed the same sequence types in different water samples. This suggests that the acquisition of a specific resistance type, either by horizontal gene transfer or by adaptive mutation, may take place preferentially in a given habitat, in which a species is prevalent or has a higher fitness than the others. In other words, the success of resistance acquisition may depend on the fitness of the target bacterium (receptor of horizontal gene transfer or mutant) in a specific environment.

\section{Conclusions}

The patterns of Aeromonas species and antimicrobial resistance varied over different parts of the urban water cycle;

In each type of water, the antimicrobial resistance patterns were primarily function of the prevailing species;

In raw surface and waste water no strong evidences for clonal dissemination of antimicrobial resistance were detected;

Water ozonation imposed a bottleneck on species diversity, with evidences of clonal selection, and promoted a significant reduction of quinolone resistance and the increase of cphA metallo-beta-lactamase;

Waste water aeromonads, particularly A. media and A. punctata, were confirmed as relevant environmental harbours of quinolone resistance, either chromosomally ( gyrA mutation) or plasmid encoded (qnrS and $\operatorname{aac}\left(6^{\prime}\right)-\mathrm{Ib}-\mathrm{cr}$ ).

Water aeromonads were confirmed as relevant agents for antimicrobial resistance spreading in the environment, which presence in tap water could be significantly reduced by water chlorination.

\section{Acknowledgements}

Authors gratefully acknowledge Prof. P. Nordmann, Dr. L.M. Cavaco, and Prof. M. Wang for the positive controls for the detection of the genes qnrA, qnrB and qnrS; qnrD and $a a c\left(6^{\prime}\right) I b$ $\mathrm{cr}$; and qnrC, respectively. This study was financed by Fundação para a Ciência e a Tecnologia (projects PTDC/AMB/70825/ 2006; PTDC/AMB/71236/2006, IVM grant SFRH/BD/27978/2006; MS grant Integration into Research)

\section{R E F E R E N C E S}

Abulhamd, A.T., 2009. Characterization of Aeromonas hydrophila isolated from aquatic environments using phenotypic and genotyping methods. Research Journal of Agriculture and Biological Sciences 5, 923-931.

Aminov, R.I., 2009. The role of antibiotics and antibiotic resistance in nature. Environmental Microbiology 11 (12), 2970-2988.

Arias, A., Seral, C., Navarro, F., Miro, E., Coll, P., Castillo, F.J., 2010a. Plasmid-mediated QnrS2 determinant in an Aeromonas caviae isolate recovered from a patient with diarrhoea. Clinical Microbiology and Infectious Diseases 16, 1005-1007.

Arias, A., Seral, C., Gude, M.J., Castillo, F.J., 2010b. Molecular mechanisms of quinolone resistance in clinical isolates of Aeromonas caviae and Aeromonas veronii bv. sobria. International Microbiology 13, 135-141.

Balsalobre, L.C., Dropa, M., Lincopan, N., Mamizuka, E.M., Matté, G.R., Matté, M.H., 2009. Detection of metallo- $\beta$ lactamases-encoding genes in environmental isolates of Aeromonas hydrophila and Aeromonas jandaei. Letters in Applied Microbiology 49, 142-145.

Baquero, F., Martínez, J.-L., Cantón, R., 2008. Antibiotics and antibiotic resistance in water environments. Current Opinion in Biotechnology 19, 260-265.

Biscardi, D., Castaldo, A., Gualillo, O., Fuscos, R., 2002. The occurrence of cytotoxic Aeromonas hydrophila strains in Italian mineral and thermal waters. Science of the Total Environment 292, 255-263.

Blasco, M.D., Esteve, C., Alcaide, E., 2008. Multiresistant waterborne pathogens isolated from water reservoirs and cooling systems. Journal of Applied Microbiology 105 (2), 469-475.

Cattoir, V., Poirel, L., Rotimi, V., Soussy, C.J., Nordmann, P., 2007. Multiplex PCR for detection of plasmid-mediated quinolone resistance qnr genes in ESBL-producing enterobacterial isolates. Journal of Antimicrobial Chemotherapy 60, 394-397.

Cattoir, V., Poirel, L., Aubert, C., Soussy, C.J., Nordmann, P., 2008. Unexpected occurrence of plasmid-mediated quinolone resistance determinants in environmental Aeromonas spp. Emerging Infectious Diseases 14, 231-237.

Cavaco, L.M., Hasman, H., Xia, S., Aarestrup, F.M., 2009. qnrD, a novel gene conferring transferable quinolone resistance in Salmonella enterica serovar Kentucky and Bovismorbificans 
strains of human origin. Antimicrobial Agents and Chemotherapy 53, 603-608.

Clinical and Laboratory Standards Institute, 2007. M100-S17. Performance Standards for Antimicrobial Susceptibility Testing, vol. 27, Wayne, PA.

Corry, J.E.L., Curtis, G.D.W., Baird, R.M., 2003. Handbook of Culture Media for Food Microbiology, vol. 34. Elsevier Science BV, Amsterdam, The Netherlands, pp. 331.

Cummings, D., Archer, K.F., Arriola, D.J., Pieter, A.B., Faucett, K.G., Laroya, J.B., Pfeil, K.L., Ryan, C.R., Ryan, K.R.U., Zuill, D.E., 2011. Broad dissemination of plasmid-mediated quinolone resistance genes in sediments of two urban coastal wetlands. Environmental Science \& Technology 45, 447-454.

DiPersio, J.R., Deshpande, L.M., Biedenbach, D.J., Toleman, M.A., Walsh, T.R., Jones, R.N., 2005. Evolution and dissemination of extended-spectrum â-lactamase-producing Klebsiella pneumoniae: epidemiology and molecular report from the SENTRY Antimicrobial Surveillance Program (1997-2003). Diagnostic Microbiology \& Infectious Disease 51, 1-7.

Dixon, B., 2008. Natural disaster microbiology. Microbe 3 , 312-313.

Faria, C., Vaz-Moreira, I., Serapicos, E., Nunes, O.C., Manaia, C.M., 2009. Antibiotic resistance in coagulase negative staphylococci isolated from wastewater and drinking water. Science of the Total Environment 407, 3876-3882.

Ferreira da Silva, M., Tiago, I., Veríssimo, A., Boaventura, A.R., Nunes, O.C., Manaia, C.M., 2006. Antibiotic resistance of enterococci and related bacteria in an urban waste water treatment plant. FEMS Microbiololy Ecology 55, 322-329.

Ferreira da Silva, M., Vaz-Moreira, I., Gonzalez-Pajuelo, M., Nunes, O.C., Manaia, C.M., 2007. Antimicrobial resistance patterns in Enterobacteriaceae isolated from an urban waste water treatment plant. FEMS Microbiology Ecology 60, 166-176.

Figueira, V., Serra, E., Manaia, C.M., 2011. Differential patterns of antimicrobial resistance in population subsets of Escherichia coli isolated from waste- and surface waters. Science of the Total Environment 409, 1017-1023.

Giraud, E., Blanc, G., Bouju-Albert, A., Weill, F.-X., DonnayMoreno, C., 2004. Mechanisms of quinolone resistance and clonal relationship among Aeromonas salmonicida strains isolated from reared fish with furunculosis. Journal of Medical Microbiology 53, 895-901.

Gordon, L., Cloeckaert, A., Doublet, B., Schwarz, S., BoujuAlbert, A., Ganière, J.-P., Le Bris, H., Le Flèche-Matéos, A., Giraud, E., 2008. Complete sequence of the floR-carrying multiresistance plasmid pAB5S9 from freshwater Aeromonas bestiarum. Journal of Antimicrobial Chemotherapy 62 (1), 65-71.

Goñi-Urriza, M., Capdepuy, M., Arpin, C., Raymond, N., Caumette, P., Quentin, C., 2000. Impact of an urban effluent on antibiotic resistance of riverine Enterobacteriaceae and Aeromonas spp. Applied and Environmental Microbiology 66 (1), 125-132.

Goñi-Urriza, M., Arpin, C., Capdepuy, M., Dubois, V., Caumette, P., Quentin, C., 2002. Type II topoisomerase quinolone resistancedetermining regions and mutations asociated with quinolone resistance. Antimicrobial Agents and Chemotherapy 46, 350-359.

Huddleston, J.R., Zak, J.C., Jeter, R.M., 2006. Antimicrobial susceptibilities of Aeromonas spp. isolated from environmental sources. Applied and Environmental Microbiology 72 (11), 7036-7042.

Ishida, Y., Ahmed, A.M., Mahfouz, N.B., Kimura, T., El-Khodery, S. A., Moawad, A.A., Tadashi Shimamoto, T., 2010. Molecular analysis of antimicrobial resistance in Gram-negative bacteria isolated from fish farms in Egypt. Journal of Veterinary Medical Science 72 (6), 727-734.
Janda, J.M., Abbott, S.L., 2010. The genus Aeromonas: taxonomy, pathogenicity, and infection. Clinical Microbiology Reviews 23, $35-73$.

Jukes, T.H., Cantor, C.R., 1969. Evolution of protein molecules. In: Mammalian Protein Metabolism, vol. 3. Academic Press, Munro, pp. 21-132. Academic Press, NY.

Khajanchi, B.K., Fadl, A.A., Borchardt, M.A., Berg, R.L., Horneman, A.J., Stemper, M.E., Joseph, S.W., Moyer, N.P., Sha, J., Chopra, A.K., 2010. Distribution of virulence factors and molecular fingerprinting of Aeromonas species isolates from water and clinical samples: suggestive evidence of water-to-human transmission. Applied and Environmental Microbiology 76, 2313-2325.

Kim, J.H., Hwang, S.Y., Son, J.S., Han, J.E., Jun, J.W., Shin, S.P., Choresca Jr., C., Choi, Y.J., Park, T.H., Park, S.C., 2011. Molecular characterization of tetracycline- and quinoloneresistant Aeromonas salmonicida isolated in Korea. Journal of Veterinary Science 12 (1), 41-48.

Kivanc, M., Yilmaz, M., Demir, F., 2011. The occurrence of Aeromonas in drinking water, tap water and the porsuk river. Brazilian Journal of Microbiology 42, 126-131.

Kühn, I., Huys, G., Coopman, R., Kersters, K., Janssen, P., 1997. A 4-year study of the diversity and persistence of coliforms and Aeromonas in the water of a Swedish drinking water well. Canadian Journal of Microbiology 43, 9-16.

Kümmerer, K., 2009. Antibiotics in the aquatic environment a review - part II. Chemosphere 75, 435-441.

Lamy, B., Kodjo, A., Laurent, F.colBVH Study Group, 2009. Prospective nationwide study of Aeromonas infections in France. Journal of Clinical Microbiology 47, 1234-1237.

Lane, D.J., 1991. 16S/23S rRNA sequencing. In: Stackebrandt, E., Goodfellow, M. (Eds.), Nucleic Acid Techniques in Bacterial Systematics. Wiley, Chichester, pp. 115-175.

Lautenschlager, K., Boon, N., Wang, Y., Egli, T., Hammes, F., 2010. Overnight stagnation of drinking water in household taps induces microbial growth and changes in community composition. Water Research 44 (17), 4868-4877.

Maalej, S., Mahjoubi, A., Elazri, C., Dukan, S., 2003. Simultaneous effects of environmental factors on motile Aeromonas dynamics in an urban effluent and in the natural seawater. Water Research 37, 2865-2867.

Miñana-Galbis, D., Urbizu-Serrano, A., Farfán, M., Fusté, M.C., Lorén, J.G., 2009. Phylogenetic analysis and identification of Aeromonas species based on sequencing of the cpn60 universal target. International Journal of Systematic and Evolutionary Microbiology 59, 1976-1983.

Miyahara, E., Nishie, M., Takumi, S., Miyanohara, H., Nishi, J., Yoshiie, K., Oda, H., Takeuchi, M., Komatsu, M., Aoyama, K., Horiuchi, M., Takeuchi, T., 2011. Environmental mutagens may be implicated in the emergence of drug-resistant microorganisms. FEMS Microbiology Letters 317, 109-116.

Novo, A., Manaia, C.M., 2010. Factors influencing antibiotic resistance burden in municipal waste water treatment plants. Applied Microbiology and Biotechnology 87, 1157-1166.

Pablos, M., Rodríguez-Calleja, J.M., Santos, J.A., Otero, A., GarcíaLópez, M.L., 2009. Occurrence of motile Aeromonas in municipal drinking water and distribution of genes encoding virulence factors. International Journal of Food Microbiology 135, 158-164.

Park, C.H., Robicsek, A., Jacoby, G.A., Sahm, D., Hooper, D.C., 2006. Prevalence in the United States of aac(6')-Ib-cr encoding a ciprofloxacin-modifying enzyme. Antimicrobial Agents and Chemotherapy 50, 3953-3955.

Périchon, B., Courvalin, P., Galimand, M., 2007. Transferable resistance to aminoglycosides by methylation of G1405 in $16 \mathrm{~S}$ rRNA and to hydrophilic fluoroquinolones by QepA-mediated efflux in Escherichia coli. Antimicrobial Agents and Chemotherapy 51, 2464-2469. 
Picão, R.C., Poirel, L., Demarta, A., Silva, C.S., Corvaglia, A.R., Petrini, O., Nordmann, P., 2008. Plasmid-mediated quinolone resistance in Aeromonas allosaccharophila recovered from a Swiss lake. Journal of Antimicrobial Chemotherapy 62, 948-950.

Rodríguez-Martínez, J.-M., Nordmann, P., Ronco, E., Poirel, L., 2010. Extended-spectrum cephalosporinase in Acinetobacter baumannii. Antimicrobial Agents and Chemotherapy 54 (8), 3484-3488.

Schwartz, T., Kohnen, W., Jansen, B., Obst, U., 2003. Detection of antibiotic-resistant bacteria and their resistance genes in wastewater, surface water, and drinking water biofilms. FEMS Microbiology Ecology 43, 325-335.

Seifrtová, M., Pena, A., Lino, C.M., Solich, P., 2008. Determination of fluoroquinolone antibiotics in hospital and municipal wastewaters in Coimbra by liquid chromatography with a monolithic column and fluorescence detection. Analytical Bioanalytical Chemistry 391, 799-805.

Servais, P., Passerat, J., 2009. Antimicrobial resistance of fecal bacteria in waters of the Seine river watershed (France). Science of the Total Environment 408, 365-372.

Szczepanowski, R., Linke, B., Krahn, I., Gartemann, K.-H., Gützkow, T., Eichler, W., Pühler, A., Schlüter, A., 2009. Detection of 140 clinically relevant antibiotic resistance genes in the plasmid metagenome of wastewater treatment plant bacteria showing reduced susceptibility to selected antibiotics. Microbiology 155, 2306-2319.

Tamura, K., Dudley, J., Nei, M., Kumar, S., 2007. MEGA4: molecular 572 Evolutionary genetics analysis (MEGA) software version 4.0 Molecular Biology and Evolution 24, 1596-1599.

Taylor, N.G.H., Verner-Jeffreys, D.W., Baker-Austin, C., 2011. Aquatic systems: maintaining, mixing and mobilising antimicrobial resistance? Trends in Ecology and Evolution 26 (6), 278-284.
Vaz-Moreira, I., Nunes, O.C., Manaia, C.M., 2011. Diversity and antibiotic resistance patterns of Sphingomonadaceae isolates from drinking water. Applied and Environmental Microbiology 77 (16), 5697-5706.

Walsh, T.R., Stunt, R.A., Nabi, J.A., MacGowan, A.P., Bennett, P.M., 1997. Distribution and expression of beta-lactamase genes among Aeromonas spp. Journal of Antimicrobial Chemotherapy 40, 171-178.

Wang, M., Guo, Q., Xu, X., Wang, X., Ye, X., Wu, S., Hooper, D.C., Wang, M., 2009. New plasmid-mediated quinolone resistance gene, gnrC, found in a clinical isolate of Proteus mirabilis. Antimicrobial Agents and Chemotherapy 53, 1892-1897.

World Health Organization, 2008. Guidelines for drinking water, third ed. WHO, Geneva.

Xi, C., Zhang, Y., Marrs, C.F., Ye, W., Simon, C., Foxman, B., Nriagu, J., 2009. Prevalence of antibiotic resistance in drinking water treatment and distribution systems. Applied and Environmental Microbiology 75 (17), 5714-5718.

Xia, S., Hendriksen, R.S., Xie, Z., Huang, L., Zhang, J., Guo, W., Xu, B., Ran, L., Aarestrup, F.M., 2009. Molecular characterization and antimicrobial susceptibility of Salmonella isolates from infections in humans in Henan Province, China. Journal of Clinical Microbiology 47, 401-409.

Xia, R., Guo, X., Zhang, Y., Xu, H., 2010. qnrVC-like gene located in a novel complex class 1 integron harboring the ISCR1 element in an Aeromonas punctata strain from an aquatic environment in Shandong Province, China. Antimicrobial Agents and Chemotherapy 54, 3471-3474.

Yáñez, M.A., Catalán, V., Apráiz, D., Figueras, M.J., MartínezMurcia, A.J., 2003. Phylogenetic analysis of members of the genus Aeromonas based on gyrB gene sequences. International Journal of Systematic and Evolutionary Microbiology 53, 875-883. 